\title{
Developing a Mathematics Lesson Plan based on Visual Learning Technology
}

\author{
Jamal Raiyn
}

\author{
Computer Science Department, Al Qasemi Academic College, Baqa El Gharbia, Israel
}

\begin{abstract}
Various researchers have highlighted the importance of the introduction of visual learning in mathematics. Visual representation in mathematics is important for teachers and for pupils in their teaching and learning of mathematics, respectively. Various visual learning platforms are used in mathematics. This research concentrates on 2-D and 3-D visual learning technologies such as MIT App Inventor and Kudo Game Lab for elementary school.
\end{abstract}

Index Terms: Visual learning tools, MIT App Inventor, Kodu Game Lab.

(C) 2016 Published by MECS Publisher. Selection and/or peer review under responsibility of the Research Association of Modern Education and Computer Science.

\section{Introduction}

This paper introduces a lesson plan using visual learning tools. Visual learning tools help students understand material and promote their interaction in the classroom (Bower \& Hayden, 1992). Visual learning tools are based on 2-D and 3-D visual environments. The new generation of tools, known as I-Generation tools, uses mobile devices such iPad, iPhone, iPod and laptops in perfect form, and apps, to develop students' mathematical thinking (Larkin et. al., 2015). Mobile technologies offer more visual and interactive forms of learning. The teacher promotes students' use of mobile technologies in order to deepen the teacher's understanding of the role and the affordances of mobile learning and its effects on students during their interaction with mathematics apps (Hildebrandt, 1998). This research has important implications for the design of such mathematical apps. Traditional learning methods in elementary school (explanation, exercise, homework etc.) are still important for pedagogical development but recently, more researchers are promoting more modern techniques that focus on a student's independent activity, the organization of self-learning environments, and experimental and practical training, (McCrudden \& Rapp, 2015). (Al-Qirim et. al., 2015).

* Corresponding author.

E-mail address: raiyn@qsm.ac.il 
We see initiatives such as the Hour of Code making claims that learning to program will lead to improved problem solving, critical thinking skills, and academic outcomes (Voogt et. al., 2015). Visual interactive learning promotes collaborative learning, and the problem solving environments involved are complex digital performance spaces, important for both learning and for assessment. Virtual performance assessment, such as a game-based assessment of scientific thinking was created at Harvard (Clarke-Midura et. al., 2012, Leonard \& Tracy, 1993).

This paper is organized as follows: Section 2 gives an overview of visual coding. Section 3 describes a lesson plan in mathematics. Section 4 and section 5 presents a mathematics lesson using visual learning tools, such as the visual environment based MIT App Inventor and Kodu Game Lab. Section 6 and section 7 discussed visual learning environment and concludes the paper.

\section{Related Works}

This section gives an overview about the use of visual tools in education. Rodger et al. (2009) introduced the integration of the Alice 3D in Middle school and designed lessons in Math, science, languages arts, social studies, and technology. Alice is an innovative 3D visual programming environment on which users can use and create an interactive games, animations, and videos. Alice is an available free teaching tool designed to create object-oriented programming. Ben-Ari (2012) introduced Scratch as a visual programming interactive media in order to support the development of computational thinking skills. Wilson et al., (2009) introduced Games-based learning, such as Scratch, and games-based construction in primary education to engaging children at primary level in computer programming skills.

With Scratch, users can program an interactive stories, games, and animations. Scratch helps young people learn to think creatively. Stolee and Fristoe (2011) used Kodu Game Lab to introduce children to programming in early ages. Kodu is a 3D visual programming platform. Kodu can be used to teach creativity, problem solving, as well as programming. Ioannidou A. (2011) used game to support and develop computational thinking skills and to promote and increase the opportunities for computer science education in the regular curriculum. Hero at.al. (2015) used the visual programming platform, MIT App, to increase the interest and skills in computational practices. The visual programming platform, MIT App, allows users to create and design android apps like games and more. MIT app can be used in various fields. MIT's App Inventor platform is used to learn and teach how to program and create mobile apps. The available materials of the MIT App Inventor platform are suitable for teaching courses for middle school, high school, and college. Peluso and Sprechini (2012) used Alice to make statement about the attitudes of high school student toward computer science. The students expressed their satisfaction toward the use of Alice visual programming. The most common programming concepts gained through visual programming environments are the loops (iteration), conditional statements that support problem solving, logic, reasoning and system thinking. We conclude that the development of educational visual programming environments such as, Alice, Scratch, Kodu, and Greenfoot, support the development of algorithmic thinking. Computational thinking includes logical thinking and algorithm thinking which involve other kind of thought processes, such as, reasoning, pattern matching, and recursive thinking. (Wing, J.M, 2010).

\section{A Lesson Plan in Mathematics}

In this section, we introduce a lesson plan in mathematics, as illustrated in Figure 1. The lesson presents several ways to introduce the concept of the remainder and its applications. The teacher uses various ways to present the material such as interactive visual learning tools (Oldfield, 1991), and interactive 2-D and 3-D games like MIT App Inventor and Kodu Game Lab. 


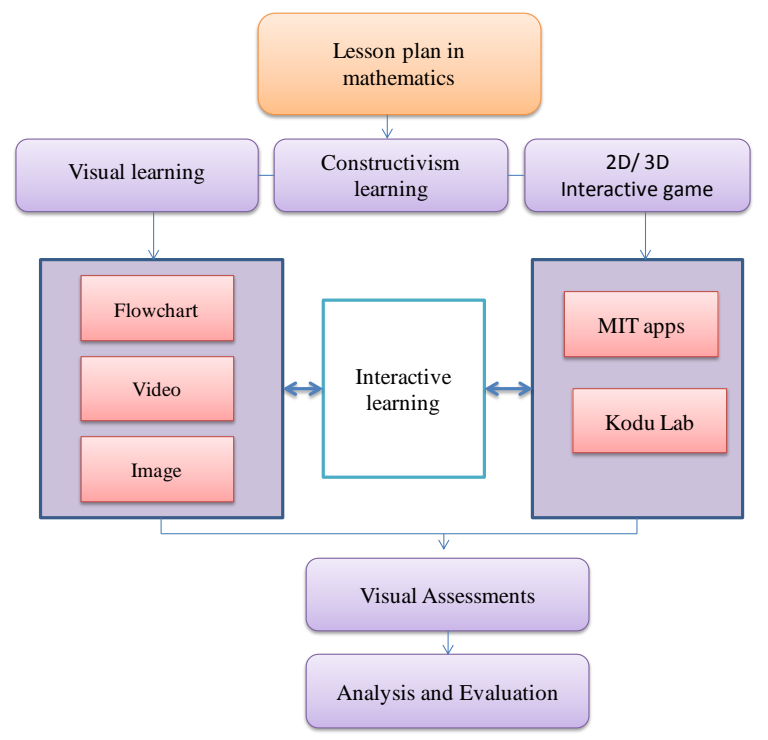

Fig.1. Lesson Plan

The number that remains after dividing a number is called a remainder. The remainder must be less than the divisor.

\begin{tabular}{|c|c|}
\hline \multicolumn{2}{|c|}{$13 / 4=3$ remainder 1} \\
\hline Divisor & 4 \\
\hline Dividend & 13 \\
\hline Remainder & 1 \\
\hline Quotient & 3 remainder 1 \\
\hline
\end{tabular}

Fig.2. Breakdown of a Division Problem

Example: Arrange 13 trees in 4 equal sets

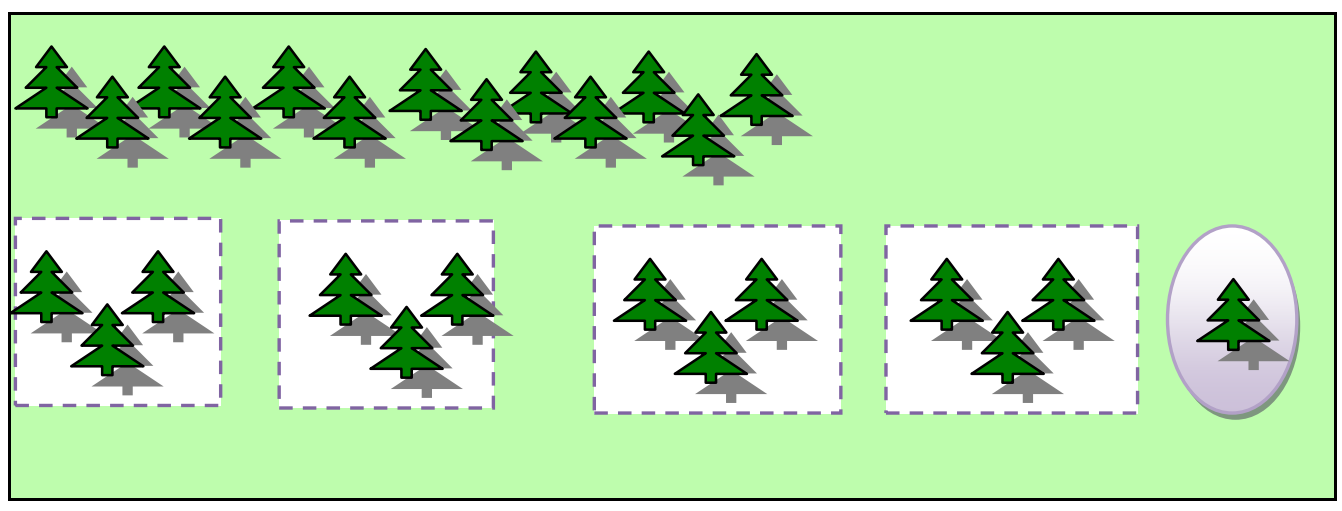

Fig.3. Visual Division Problem with a Remainder 


\subsection{Modulo in Code}

Presenting a mathematics lesson via a visual environment promotes interactivity. Furthermore, visual coding offers students various ways to learn autonomy. At an early age, students get to know algorithmic process terms, such as input data, processing data, and output data. This method helps students to develop their thinking in visual algorithms.

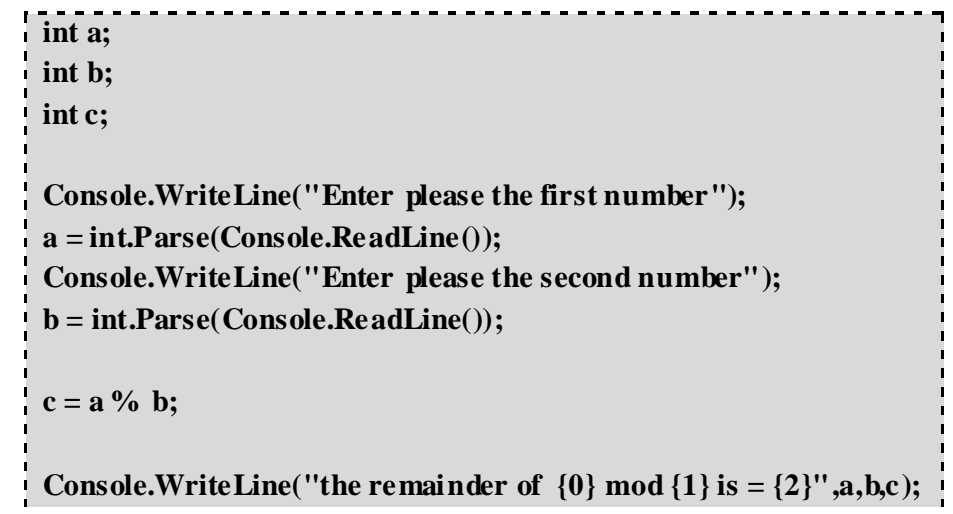

Fig.4. Segnet of Visual Code

\subsection{Modulo in Automata}

Figure 5 illustrates words (in the computer sciences sense) that are numbers divided by 3 with remainder 2. Presenting some mathematical problems in form of deterministic finite automata (DFA) can strengthen problem finding skills in students.

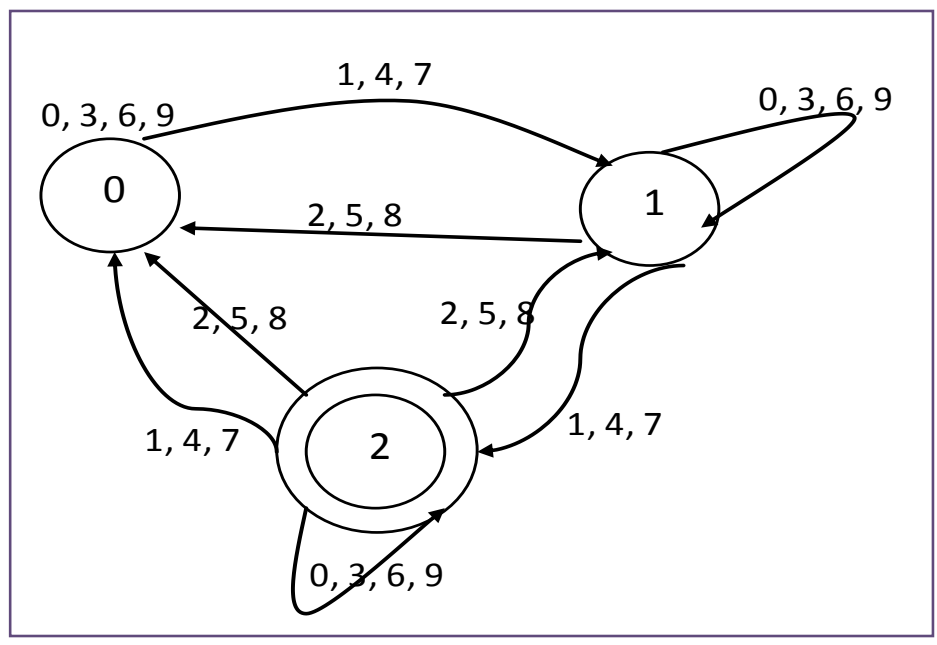

Fig.5. Remainder in DFA

\section{Mobile Technology in Mathematics Education}

Nowadays, technology development is trending toward mobile devices and touch screen touch technologies. 


\subsection{MIT App Inventor}

MIT Apps Inventor is a visual programming platform that enables the user to create and design apps for smart phones operated by the Android system. MIT App Inventor consists of two layers. The first is a design layer, where the user can select components and objects for an app, the second is a blocks editor based on logic units that are used to program behaviors and actions. This section introduces an interactive activity based on MIT App Inventor in mathematics. The use of App in the classroom aims to increase students' interest in computational practices.
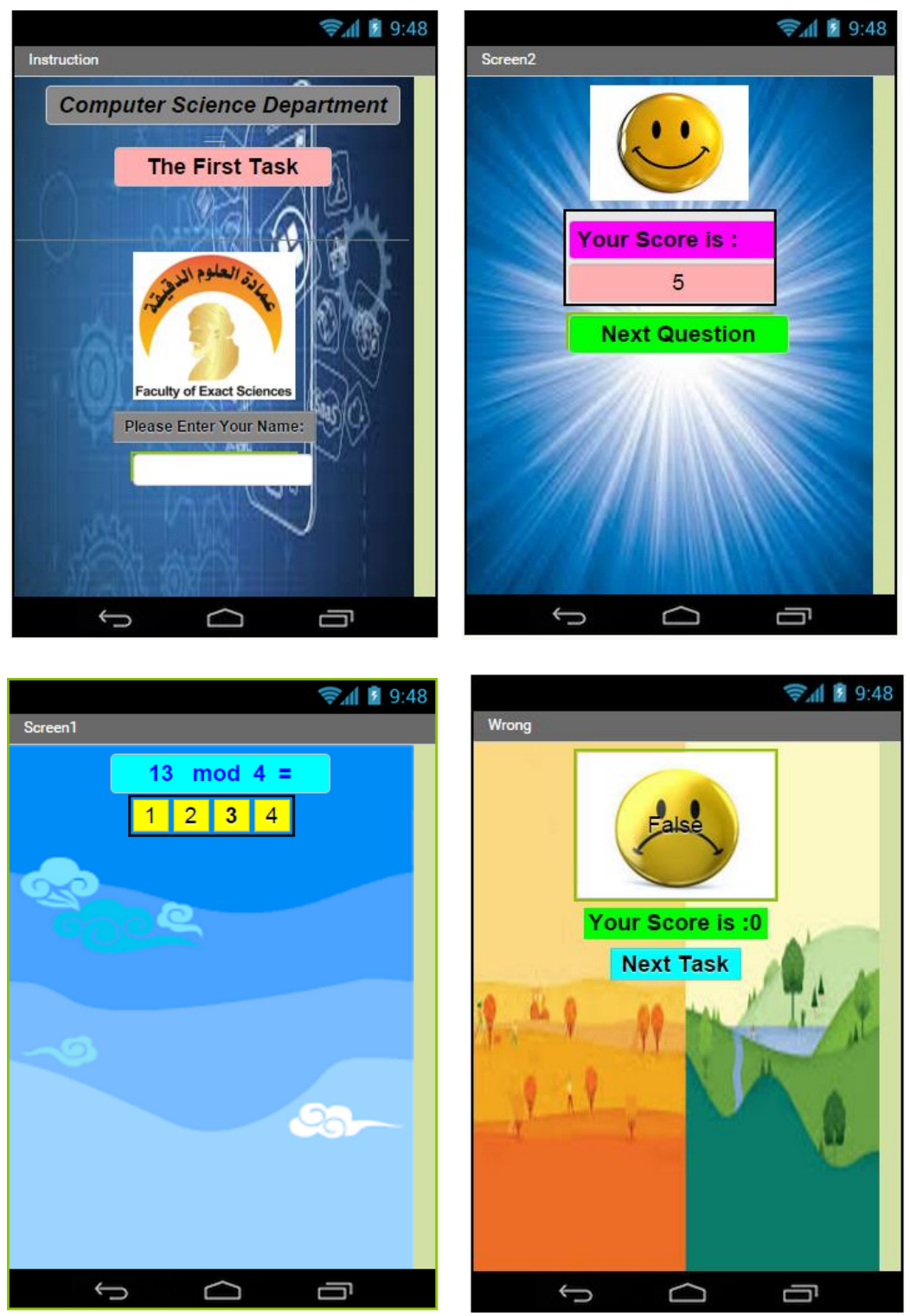

Fig.6. Mit App Inventor Mathematics Problem 


\section{Interactive 3D Visual Platform}

Kodu Game Lab is an application used to create interactive educational games in 3-D visual environments. Users can design the space and can add objects and characters. Furthermore, users can program each character individually, as well as, interactions between objects. Kodu games promote the collaboration among students through problem solving. Figure 7 illustrates the design view of a game that was created to help students to understand the remainder in mathematics.

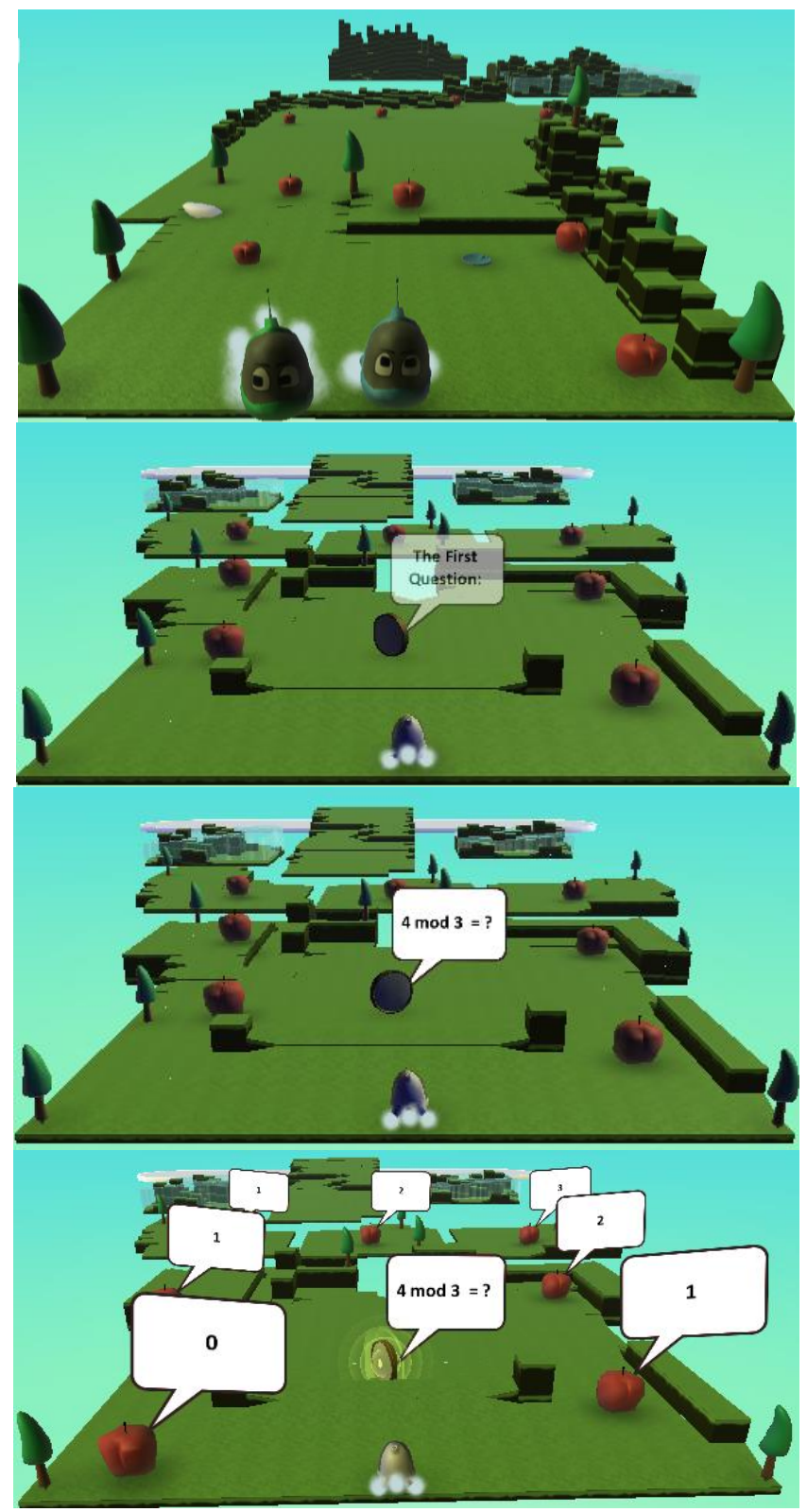

Fig.7. Kodu Game Lab Mathematics Game Design 


\section{Programming in Kodu Game Lab}

Programming in Kodu Game Lab involves the programming of objects and their features. The program consists of the condition and action for each rule. The ordering of the rules is very important. Figure 8 illustrates the condition of each rule on the left, and the action on the right. For the Kodu program, when the keyboard arrow is pressed, act on the direction indicated; the action move forward quickly.

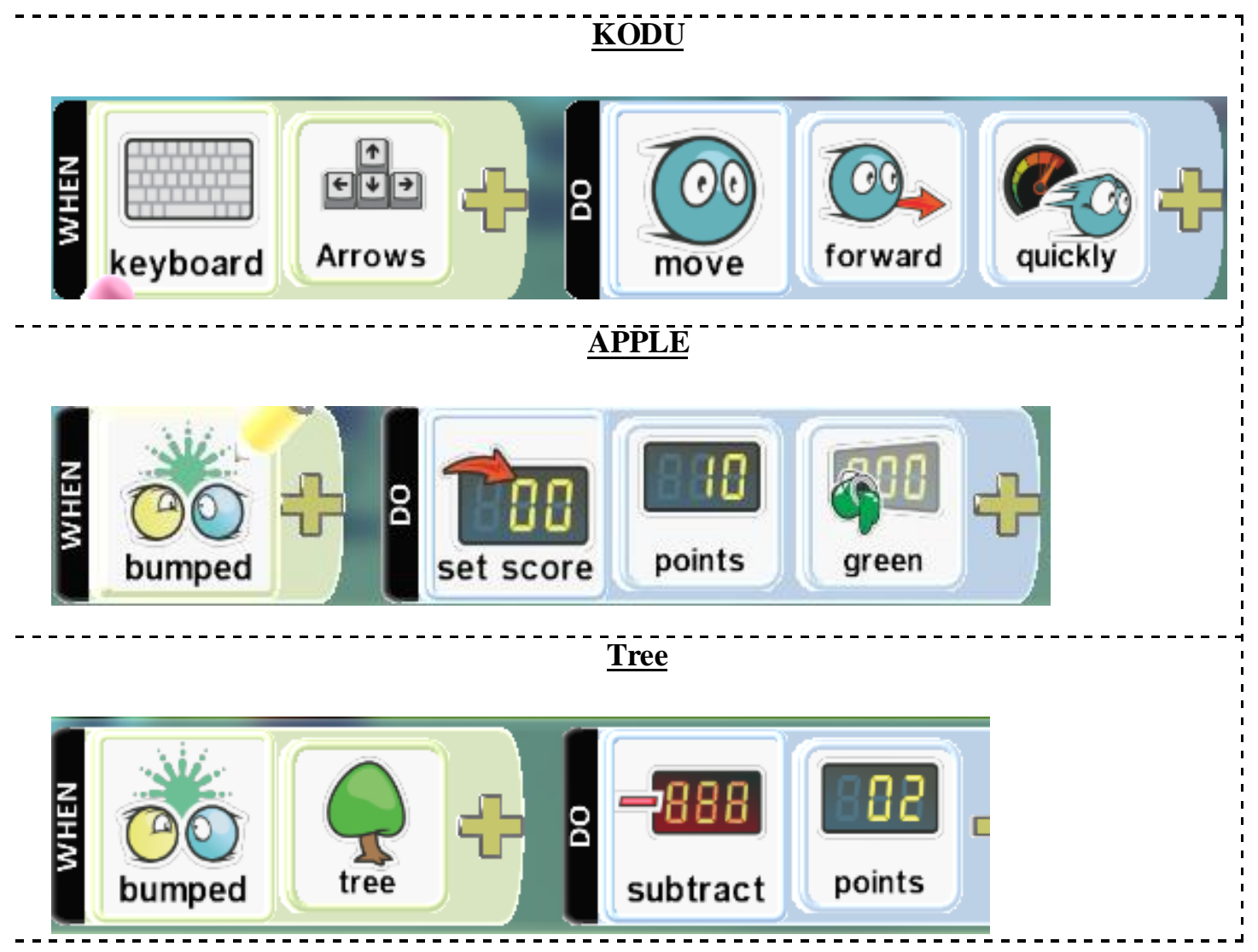

Fig.8. Kodu Game Lab Programming Interface

\section{Discussion and Conclusions}

In this article, we have introduced a lesson in mathematics, framed in terms of both traditional learning tools and in visual interactive learning tools. Traditional learning uses conventional practice, however, visual learning tools used various techniques to promote meaningful interactive learning. In this paper, we present some results of our research concerning the use of visual learning for mobile devices. Figure 9 shows that visual interactive learning increases higher order thinking skills in students compared to traditional learning techniques. For the higher order thinking skills of selection, ordering, and contrasting, the differences between visual and traditional learning are clear. These advantages can be obtained using visual learning application. 


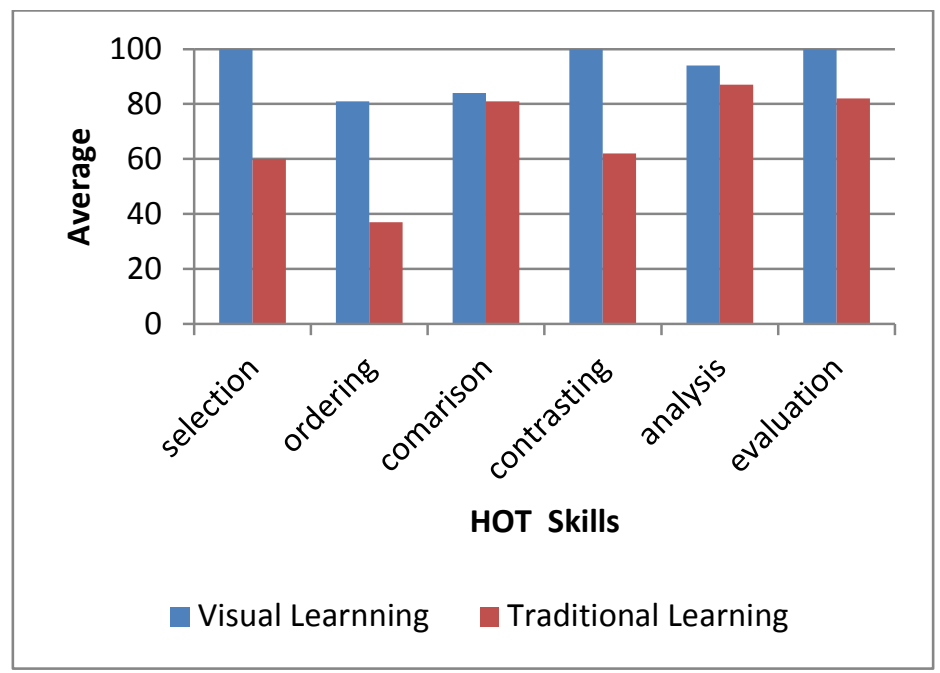

Fig.9. HOT Skills

\section{References}

[1] Al-Qirim N, Mesmari A, Mazroeei K, Khatri S, Kaabi Z. Developing teaching scenarios in the classroom using interactive smart board ecosystem, Digital Ecosystems and Technologies (DEST), 2010 4th IEEE International Conference 13-16 April 2010; 525-530. doi: 10.1109/DEST.2010.5610596.

[2] Ben-Ari, M. and Resnick M. (2015). New frameworks for studying and assessing the development of computational thinking, Computer Science Education, (online).

[3] Bower N, Hayden R. Fascinating literary theory play early. Childhood Education, 25(2), 1992. 16-17.

[4] Clarke-Midura J, Dede C. Assessment, Technology, and Change. Journal of Research, Education and Technology, 42(3), 2010, 309-328.

[5] Herro, D. and McCune-Gardner, C. and Boyer, M.D. (2015). Perceptions of Coding with MIT App Inventor: Pathways for their Future. JOURNAL FOR COMPUTING TEACHERS.

[6] Hildebrandt C. Developing mathematical understanding through invented games. Teaching Children Mathematics, 5(1), 1998. 191-95.

[7] Ioannidou A. (2011). Computational Thinking Patterns, Annual Meeting of the American Educational Research Association (AERA).

[8] Larkin K, Calder, N. Mathematics education and mobile technologies, Math Ed Res J (2016) 28: 2005. 17. DOI 10.1007/s13394-015-0167-6.

[9] Leonard LM., Tracy D.M. Using games to meet the standards for middle school students. Arithmetic Teacher, 40(3), 1993. 499-501.

[10] McCrudden TM, Rapp DN. How Visual Displays Affect Cognitive Processing, Educational Psychology Review, 2015.

[11] Oldfield, BJ. Game in the learning. Mathematics in School, 20(3), 2015. 16-18.

[12] Peluso, E.M., and Sprechini, G. (2012). The impact of Alice on the Attitudes of High School students Toward Computing, Journal for Computing Teachers, 7, 2012.

[13] Rodger et.al. (2009).Engaging Middle School Teachers and Students with Alice in a Diverse Set of Subjects.SIGCSE09, March 3-7, 2009.

[14] Stolee, T.K., and Fristoe, T. (2011). Exprssing computer science concepts through Kodu Game Lab, SIGCSE'11, March 9-12, 2011, Dalla, Texas, USA. 
[15] Voogt J, Fisser P, Good J, Mishra P, Yada A. Computational thinking in compulsory education: Towards an agenda for research and practice. Educaction Informtion Technology. 2015. DOI 10.1007/s10639-0159412-6.

[16] Wilson, K.A. Bedwell, W.L. and Lazzara E.L. et al.(2009), Relationships between game attributes and learning outcomes: review and research proposals, Simulation \& Gaming, vol. 40, no. 2, pp. 217-266.

[17] Wing, J. M. (2010). Computational Thinking: What and Why? The Link Newsletter, Retrieved from http://www.cs.cmu.edu/ CompThink/papers.html.

\section{Authors' Profiles}

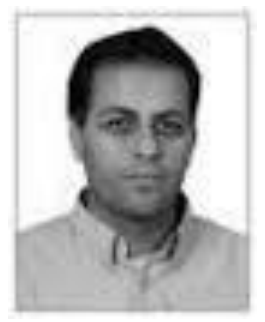

Jamal Raiyn received the MS degree in mathematics and computer science from Hannover University in Germany, in 2000 and he finished the PhD study at Leibniz University of Hannover in Germany. In June 2010 he finished his Postdoctoral at the Technion in Israel. Since September 2002 till now, he is Assistant Professor in computer science department at the Al-Qasemi College in Israel. Since 2010 he is the head of computer science department at Al-Qasemi College in Israel.

How to cite this paper: Jamal Raiyn,"Developing a Mathematics Lesson Plan based on Visual Learning Technology", International Journal of Education and Management Engineering(IJEME), Vol.6, No.4, pp.1-9, 2016.DOI: $10.5815 /$ ijeme.2016.04.01 